\title{
The role of BDNF/TrkB signaling in acute amphetamine- induced locomotor activity and opioid peptide gene expression in the rat dorsal striatum
}

\author{
Jacqueline F. McGinty ${ }^{1}{ }^{*}$, Alexandra J. Bache ${ }^{2}$, Nortorious T. Coleman ${ }^{1}$ and Wei-Lun Sun ${ }^{1}$ \\ 1 Department of Neurosciences, Medical University of South Carolina, Charleston, SC, USA \\ 2 Department of Psychology, College of Charleston, Charleston, SC, USA
}

\section{Edited by:}

Elizabeth Abercrombie, Rutgers -

Newark: The State University of New

Jersey, USA

\section{Reviewed by:}

Kristen Ashley Horner, Mercer

University School of Medicine, USA

Kristen Keefe, University of Utah, USA

*Correspondence:

Jacqueline F. McGinty, Department of Neurosciences, Medical University of South Carolina, 173 Ashley Avenue MSC 510, Charleston, SC 29425, USA e-mail:mcginty@musc.edu
Exposure to psychostimulants increases brain-derived neurotrophic factor (BDNF) mRNA and protein levels in the cerebral cortex and subcortical structures. Because BDNF is co-localized with dopamine and glutamate in afferents to the striatum of rats, it may be co-released with those neurotransmitters upon stimulation. Further, there may be an interaction between the intracellular signaling cascades activated by dopamine, glutamate, andTrkB receptors in medium spiny striatal neurons. In the present study, the effect of acute amphetamine administration on TrkB phosphorylation, as an indirect indicator of activation, and striatal gene expression, was evaluated. In Experiment 1, 15 min or $2 \mathrm{~h}$ after a single saline or amphetamine $(2.5 \mathrm{mg} /$ $\mathrm{kg}$, i.p.) injection, the caudate-putamen (CPu), nucleus accumbens (NAc), and dorsomedial prefrontal cortex (dmPFC) were extracted and processed for phospho (p)-TrkB immunoreactivity. Immunoprecipitation analyses indicated that neither the tyrosine phosphorylation ( $\mathrm{p}$-Tyr) or autophosphorylation sites of TrkB (706) were changed in NAc, CPu, or dmPFC 15 min after amphetamine administration. In contrast, p-Tyr and the PLC $\gamma$ phosphorylation site of TrkB (816) were increased in the NAc and CPu $2 \mathrm{~h}$ after amphetamine. In Experiment 2, intra-striatal infusion of the tyrosine kinase inhibitor, K252a, increased amphetamine-induced vertical activity but not total distance traveled. In addition, K252a inhibited amphetamine-induced preprodynorphin, but not preproenkephalin, mRNA expression in the striatum. These data indicate that acute amphetamine administration induces $\mathrm{p}$-TrkB activation and signaling in a time- and brain regiondependent manner and that TrkB/BDNF signaling plays an important role in amphetamine-induced behavior and striatal gene expression.

Keywords: dynorphin, enkephalin, neurotrophic factors, phosphorylation, psychostimulants, striatum, TrkB receptors

\section{INTRODUCTION}

Amphetamine (AMPH) triggers behavioral activation and gene expression in the striatum by integrating dopamine and glutamate inputs to medium spiny neurons (MSNs) that project to the dorsal and ventral pallidum and ventral midbrain. Activation of genes/proteins that mediate or temper the psychomotor response to stimulants is triggered primarily by D1 dopamine-Gs-coupledPKA signaling (McGinty et al., 2008). However, dopamine and glutamatergic afferents to the striatum also express brain-derived neurotrophic factor (BDNF) that activates TrkB receptors present on all MSNs (Freeman et al., 2003). Thus, there is a potential interaction between dopamine, glutamate, and BDNF/TrkB signaling in the behavioral and neurochemical response to AMPH. Overlapping signaling cascades activated by these MSN inputs suggest that the striatum responds to an initial, moderate dose of AMPH with a complex repertoire that both mediates psychomotor effects and simultaneously functions to bring the network back to homeostasis. Thus, we investigated the regulation and function of TrkB activation in the response of MSNs to acute AMPH.

AMPH activates the extracellular signal-regulated kinase (ERK)/ mitogen-activated protein kinase (ERK MAPK) cascade that leads to CREB phosphorylation and striatal opioid peptide expression
(McGinty et al., 2008). Because D1 receptors are positively coupled to adenylate cyclase, it had been assumed that the cAMP/ PKA cascade is sufficient for CaCRE-mediated gene expression subsequent to CREB phosphorylation by dopaminergic agonists. In MSNs, CREB is phosphorylated in response to dopaminergic (Cole et al., 1995; Simpson et al., 1995) and glutamatergic signals (Vanhoutte et al., 1999). In dissociated striatal cultures, CREB phosphorylation and Fos immunoreactivity induced by dopamine, the D1 dopamine agonist, SKF82958, or forskolin, is blocked by NMDA receptor antagonists (Konradi et al., 1996; Valjent et al., 2005). Therefore, phospho-CREB is thought to integrate dopaminergic and glutamatergic signals that modulate the cAMP response element (CRE)-mediated expression of target genes, such as c-fos and opioid peptides, in these neurons. CREB is also a common phosphorylation target of all three pathways activated by neurotrophins: the ERK MAPK, phosphoinositol-3 kinase (PI-3K), and phospholipase C $\gamma$ (PLC $\gamma$ ) signaling cascades (Patapoutian and Reichardt, 2001).

Brain-derived neurotrophic factor/TrkB signaling is critical for activity-dependent synaptic plasticity, the cellular basis of learning and memory, and neuroadaptations underlying drug seeking (Rattiner et al., 2004; Ou and Gean, 2006; Russo et al., 
2008; McGinty et al., 2010). The normal striatum contains little BDNF mRNA; instead it receives extensive projections from the substantia nigra and cortical pyramidal neurons that synthesize BDNF and transport the protein anterogradely to be released in an action potential and calcium-dependent manner (Sauer et al., 1994; Seroogy et al., 1994; Altar et al., 1997). The biological effects of BDNF are primarily mediated by the tropomyosin kinase receptor, TrkB (Chao, 2003), which is abundantly expressed in cortical pyramidal neurons, ventral midbrain dopamine neurons, and GABAergic striatal MSNs (Numan and Seroogy, 1999; Freeman et al., 2003). Furthermore, BDNF directly stimulates opioid peptide gene expression, as exogenous BDNF infused into the striatum (Sauer et al., 1994) or substantia nigra (Arenas et al., 1996) increases the expression of striatal MSN peptides. Conversely, BDNF deficient mice express less opioid peptide mRNA in the striatum (Saylor et al., 2006) and exhibit more prolonged hyperlocomotor activity following acute amphetamine exposure (Saylor and McGinty, 2008).

Because AMPH stimulates dopamine and glutamate transmission in these pathways, BDNF is also likely to be released and may contribute to AMPH-induced changes in striatal signaling. Direct measurement of BDNF release is problematic; however, evidence of BDNF binding to and activation of TrkB receptors can be indirectly measured by the degree of TrkB phosphorylation (Poo, 2001). Further, BDNF mRNA levels positively correlate with activity in the cerebral cortex (Rocamora, et al., 1996; Poo, 2001) and BDNF mRNA increases in many cortical areas after injection of acute cocaine or amphetamines (Le Foll, et al., 2005; Saylor and McGinty, 2008). Since BDNF regulates the constitutive expression of MSN opioid peptides, AMPH-induced opioid gene expression is dependent on ERK activation, and BDNF modifies reward-related behaviors, we have begun to investigate whether or not BDNF/ TrkB signaling contributes to AMPH-induced behavioral activity and striatal signaling.

\section{MATERIALS AND METHODS ANIMALS AND DESIGN}

All procedures were carried out in accordance with the National Institutes of Health Guide for Care and Use of Laboratory Animals (NIH Publications No. 8023, revised 1996) and were approved by the Institutional Animal Care Committee of MUSC. Adult male Sprague-Dawley rats (250-275 g; Charles River, Raleigh, NC, USA) were individually housed under standard conditions ( $12 \mathrm{~h}$ lightdark cycle; food and water ad libitum). All animals were handled daily for 5 days. On day 6 , the rats were randomly assigned to treatment groups. In Experiment 1, the rats were injected i.p. with $2.5 \mathrm{mg} / \mathrm{kg} \mathrm{D}$-amphetamine sulfate (NIDA Res Triangle Institute, $\mathrm{NC}$, USA) or saline. Fifteen minutes or $2 \mathrm{~h}$ after injection, the rats were decapitated and the PFC, nucleus accumbens (NAc), and caudate-putamen $(\mathrm{CPu})$ were dissected out for immunoblotting procedures.

In Experiment 2, on the sixth day, rats were anesthetized with an equithesin/ketamine cocktail and intracranial guide cannulae were implanted bilaterally into the dorsal striatum as described (Shi and McGinty, 2006). Rats recovered and were handled for 5 days following surgery. On the test day, rats were habituated to photocell chambers (Accuscan Instruments, Inc., Columbus, $\mathrm{OH}$,
USA). At the end of $1 \mathrm{~h}$ habituation, the striatum was infused bilaterally with $1 \mu \mathrm{l}$ of $35.7 \mathrm{mM} \mathrm{K252a}$ (a non-selective kinase inhibitor with high affinity for Trk receptors-Biomol) or 50\% DMSO vehicle (veh) at a rate of $0.25 \mu \mathrm{l} / \mathrm{min}$. The dose of $\mathrm{K} 252 \mathrm{a}$ was based on effective intracranial infusions in published studies (Ou and Gean, 2006; Whitfield, et al., 2011). After the infusions, rats were put back into the photocell chambers until they received an i.p. injection of AMPH (2.5 mg/kg) or $1 \mathrm{ml} / \mathrm{kg}$ saline (sal) $20 \mathrm{~min}$ later. Behavioral activity was recorded for $3 \mathrm{~h}$ (based on peak opioid peptide mRNA response to AMPH; Wang et al., 1995) after the i.p. injections. Immediately after behavioral testing, the rats were anesthetized with equithesin and decapitated. Brains were dissected and frozen for in situ hybridization histochemistry.

\section{WESTERN BLOTTING}

Tissue was homogenized in lysis buffer with protein phosphatase inhibitor mixtures. The protein concentration was measured with BCA assay. Equal amount of proteins $(15 \mu \mathrm{g})$ were resolved using $6 \%$ SDS-PAGE and transferred to a nitrocellulose membrane. The membrane was blocked with 5\% milk/TBST and probed with rabbit primary antiserum against TrkB, phospho-tyrosine ( $\mathrm{p}$-Tyr), $\mathrm{p}$-TrkB 706 (Cell Signaling Technology, Inc.), or p-TrkB 816 (gift of Dr. Moses Chao, NYU) overnight at $4^{\circ} \mathrm{C}$. For total TrkB, the intensity of each protein sample was normalized by calnexin (Stressgen Bioreagents). After a series of washing, membranes were incubated with HRP-conjugated anti-goat secondary antibody, the immunoreactive bands on the membrane were detected by ECL+ chemiluminescence reagents on a X-ray film. Membranes were re-probed with calnexin after stripping. Integrated density values were measured for individual bands using Image J software.

\section{IMMUNOPRECIPITATION}

The procedure for immunoprecipitation has been described previously (Sun et al., 2009). Briefly, $200 \mu \mathrm{g}$ of sample was incubated with $\operatorname{TrkB}$ antibody and protein A agarose beads. After washing with lysis buffer, Laemmli sample buffer was added to the collected beads and boiled for $5 \mathrm{~min}$. Equal amount of samples was loaded and subjected to western blotting. Membranes were probed with p-Tyr, p-TrkB 706, p-TrkB 816, or TrkB antisera. Five percent of total homogenates was used as input to normalize band intensities.

\section{MOTOR ACTIVITY RECORDING}

Horizontal activity (total distance traveled) and vertical activity (rearing) were monitored for $3 \mathrm{~h}$ in photocell chambers (Accuscan Instruments, USA). Beam breaks were recorded continuously and clustered in 5 min bins by a PC running VersaMax/Digiscan System Software (Accuscan Instruments, Inc.).

\section{IN SITUHYBRIDIZATION HISTOCHEMISTRY}

Brains were cut at $12 \mu \mathrm{m}$ through the striatum and mounted on slides. Adjacent sections were processed for Nissl-staining to detect cannula tracks and in situ hybridization histochemistry as previously described (Shi and McGinty, 2006). Briefly, the sections were fixed in buffered $4 \%$ paraformaldehyde and pre-hybridized to minimize non-specific binding. Sections were hybridized with a 48-mer ${ }^{35} \mathrm{~S}$-dATP- or ${ }^{33} \mathrm{P}$-dATP-labeled oligonucleotide encoding preprodynorphin (PPD) or preproenkephalin (PPE), washed, 

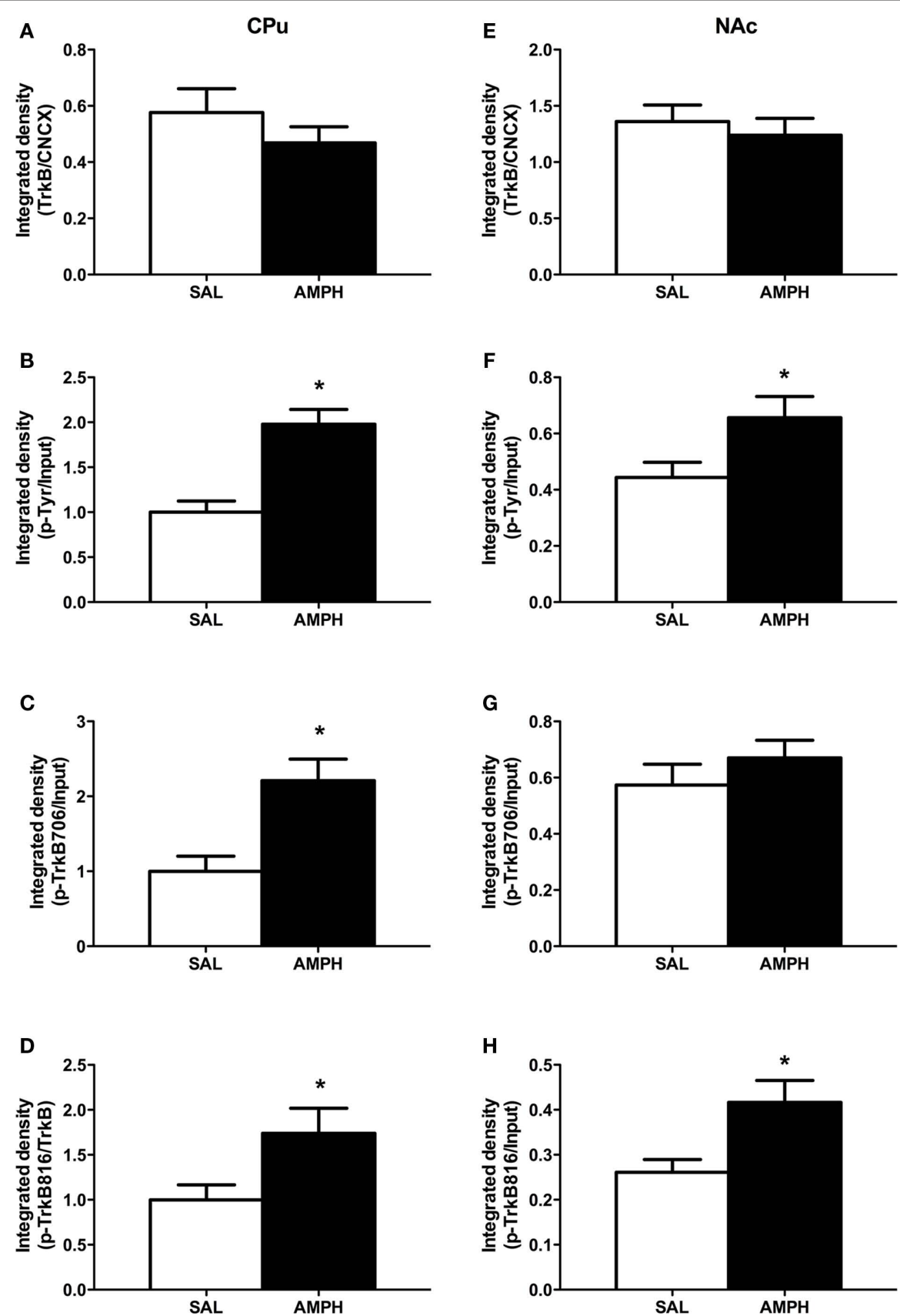

FIGURE 1 | Two hours after a single AMPH injection, TrkB phosphorylation is increased. (A) Total TrkB receptor protein level in the CPu was not altered, (B) tyrosine phosphorylation of TrkB ( $p$-Tyr) was increased in the $\mathrm{CPu},(\mathbf{C})$ autophosphorylation of TrkB ( $p$-TrkB 706) was increased in the CPu, (D) PLC $\gamma$ phosphorylation site of TrkB (p-TrkB 816) was increased in the CPu, (E) total TrkB

and dried before putting the slides on X-ray film and exposing for 1-4 weeks. The integrated density of the hybridization signals on three adjacent sections per brain was quantified by NIH Image analysis after subtracting white matter background. Under the density slice option, the hybridization signal in the entire dorsal striatum in the injected side was measured using a circle (200 pixel diameter) as described (Wang and McGinty, 1995).

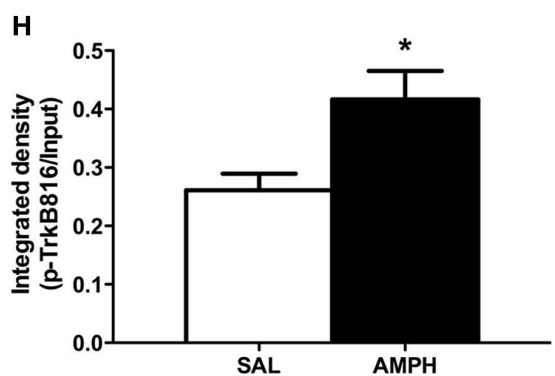

receptor protein level in the NAc was not altered, (F) tyrosine phosphorylation of TrkB (p-Tyr) was increased in the NAc, (G) autophosphorylation of TrkB (p-TrkB 706) was not increased in the NAc, (H) PLC $\gamma$ phosphorylation site of TrkB (p-TrkB 816) was increased in the NAc, ${ }^{*} p<0.05$ when compared to saline-treated group indicated by mean \pm SEM. $N=6 /$ group. 
integrated density values. When an ANOVA F-ratio was significant, multiple comparisons were made using a Student-Newman-Keuls test. Independent $t$-tests were used to analyze the difference between groups. Results were determined to be significant when $p<0.05$.

\section{RESULTS}

\section{EXPERIMENT 1: AMPH INCREASED TRKB PHOSPHORYLATION IN THE STRIATUM IN A DELAYED MANNER}

Fifteen minutes after a single AMPH injection, neither total or phospho-TrkB receptor protein levels in the dorsomedial prefrontal cortex (dmPFC), NAc, and CPu were altered (data not shown). In contrast, p-Tyr (tyrosine phosphorylation of TrkB), p-TrkB 706 (autophosphorylation site), and p-TrkB 816 (PLC $\gamma$ phosphorylation site) immunoreactivities were significantly increased in the $\mathrm{CPu} 2 \mathrm{~h}$ after amphetamine (Figures 1A-D). In the NAc at $2 \mathrm{~h}$, amphetamine significantly increased $p$-Tyr and p-TrkB 816, but not p-TrkB 706, immunoreactivity (Figures 1E-H). No differences were detected in the dmPFC $2 \mathrm{~h}$ after AMPH injection (data not shown).

\section{EXPERIMENT 2: K252A AUGMENTED AMPH-INDUCED VERTICAL ACTIVITY AND SUPPRESSED AMPH-INDUCED PPD MRNA}

AMPH-stimulated horizontal movement measured as total distance traveled and vertical activity as previously described (Shi and McGinty, 2006). Intra-striatal infusion of K252a did not alter
AMPH-induced total distance traveled but augmented AMPHinduced vertical activity (Figure 2). In situ hybridization revealed that AMPH-stimulated PPD and PPE mRNA levels in the CPu as previously described (Smith and McGinty, 1994; Shi and McGinty, 2006). Intra-striatal infusion of K252a suppressed AMPH-induced $\mathrm{PPD}$, but not PPE, mRNA levels in the CPu (Figure 3). A representative cannula placement for this experiment is illustrated in Figure 4.

\section{DISCUSSION}

Two hours, but not $15 \mathrm{~min}$, after a single AMPH injection, $\mathrm{p}$-TrkB protein expression was increased in the $\mathrm{CPu}$ and $\mathrm{NAc}$, but not in the dmPFC. Similar to a previous study (Meredith et al., 2002), total TrkB immunoreactivity was not increased $2 \mathrm{~h}$ after acute AMPH. However, in that study repeated daily AMPH injections $(5 \mathrm{mg} / \mathrm{kg}$ ) caused an increased in TrkB mRNA and/or immunoreactivity in several brain structures, including the striatum. In the present study, AMPH induces TrkB phosphorylation, a marker of TrkB receptor activation (Chao, 2003; Reichardt, 2006), in a time- and regionspecific manner. Although trans-activation and non-neurotrophinmediated activation of growth factor receptors has been reported (Huang et al., 2008; Jeanneteau et al., 2008), TrkB dimerization and phosphorylation most commonly occurs subsequent to BDNF binding (Chao, 2003). In the striatum, although the nigrostriatal track also contains BDNF, the majority of BDNF is synthesized,

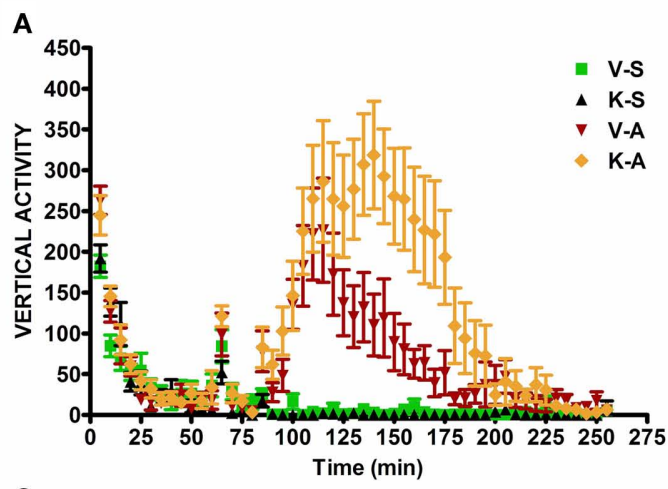

C

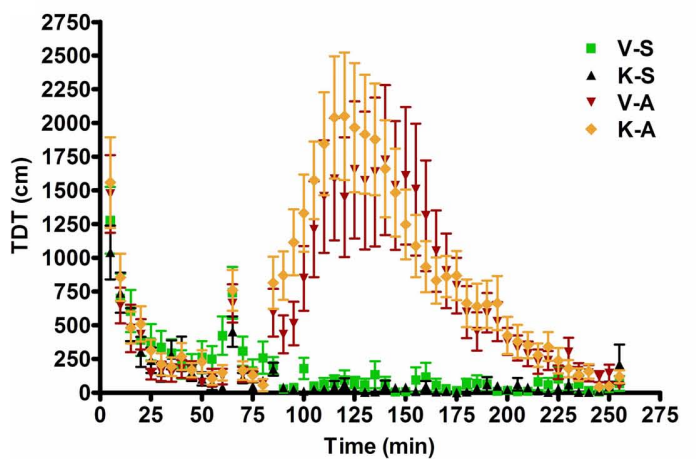

FIGURE 2 | AMPH-induced vertical activity (VA), but not total distance traveled (TDT), is augmented by K252a. (A) Vertical activity recorded for $1 \mathrm{~h}$ before intra-striatal K252a or vehicle infusion and for $3 \mathrm{~h}$ after $\mathrm{AMPH}$ or saline injection. (B) Area under the curve (AUC) analysis for $3 \mathrm{~h}$ after i.p. injections indicated by mean \pm SEM. ${ }^{*} p<0.05 \mathrm{~K}-\mathrm{A}$ vs. V-A; ${ }^{\$ \$} p<0.01 \mathrm{~K}-\mathrm{A}$ vs. K-S;

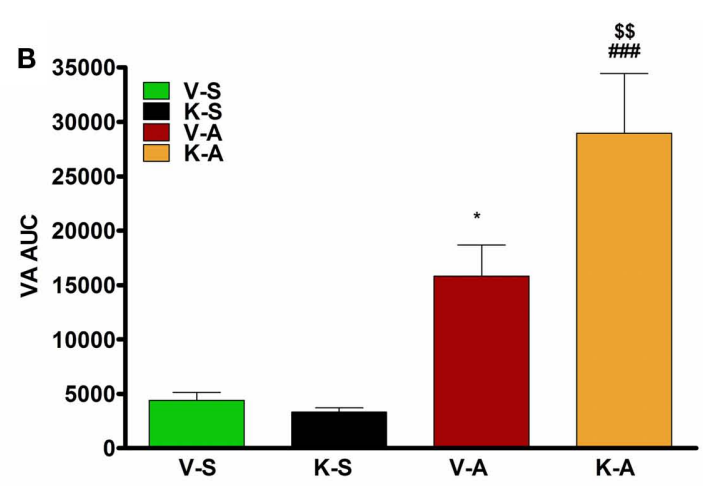

D

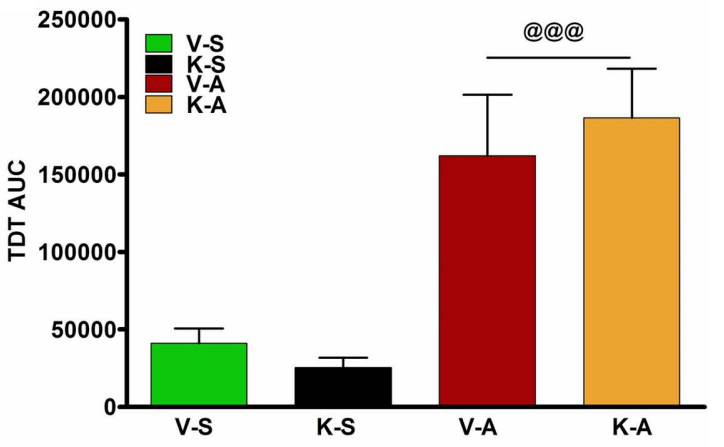

${ }^{\# \#} p<0.001$ V-A vs. V-S. (C) Activity recorded for $1 \mathrm{~h}$ before intra-striatal K252a or vehicle infusion and for $3 \mathrm{~h}$ after AMPH or saline injection. (D) Area under the curve $(A \cup C)$ analysis for $3 \mathrm{~h}$ after i.p. injections indicated by mean $\pm \mathrm{SEM}$. ${ }^{\circledR @ \Theta}=p<0.001$ vs. V-S and K-S. V-S, vehicle saline; K-S, K252a-saline; V-A, vehicle-AMPH; K-A, K252a-AMPH. N=6-8/group. 

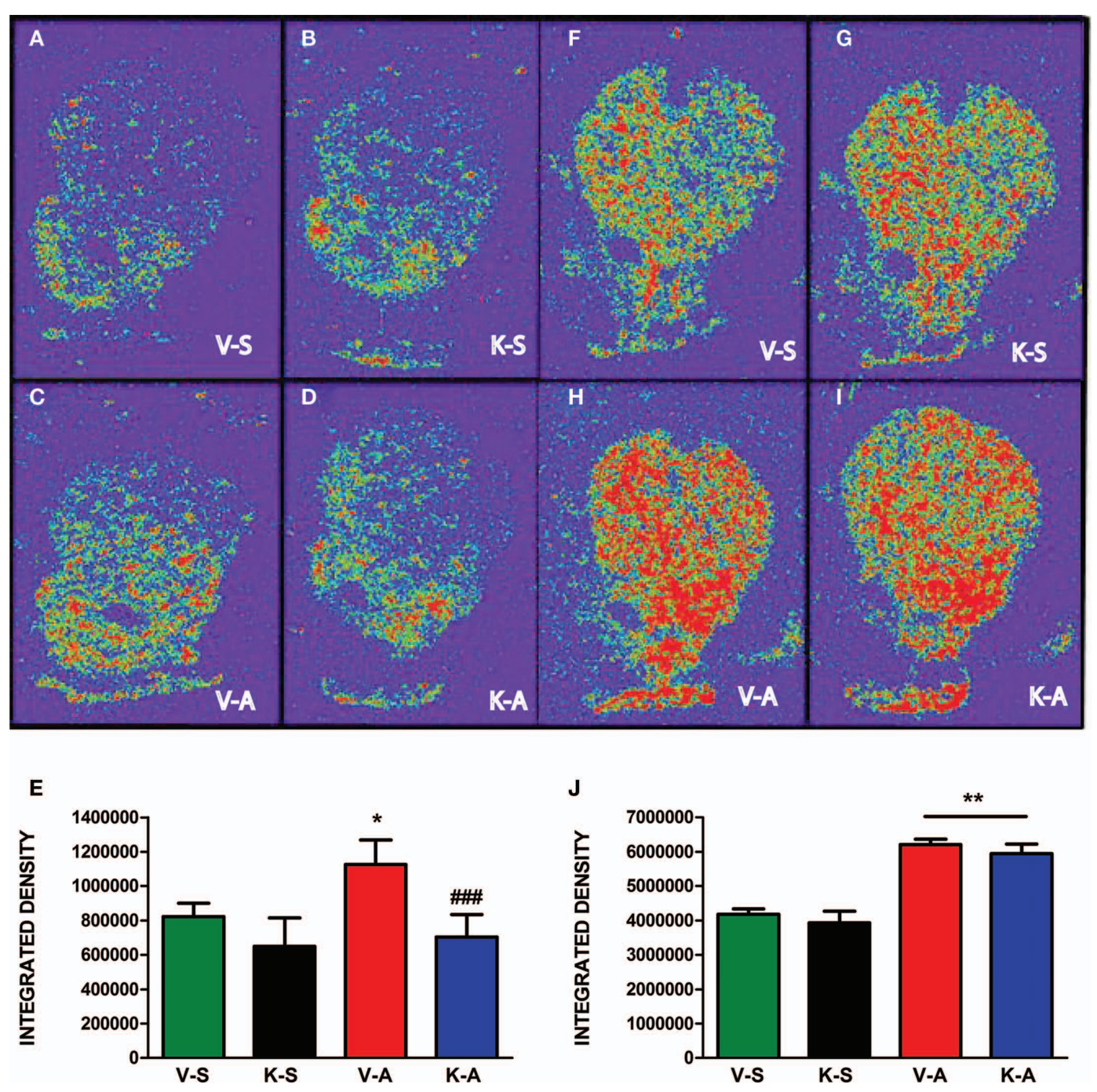

FIGURE 3 |AMPH-induced increase in PPD mRNA, but not PPE mRNA, is blocked by K252a. (A-D) PPD mRNA. (E) Integrated density measurements for PPD mRNA indicated as mean \pm SEM * $p<0.05$ vs. V-S; \#\# $p<0.001$ vs. V-A. (F-I) PPE mRNA. (J) Integrated density measurements for PPE mRNA indicated as mean \pm SEM ** $p<0.01$ vs. V-S and K-S. V-S, vehicle saline, K-S, K252a-saline; V-A, vehicle-AMPH; K-A, K252a-AMPH ( $n=6-8 / g r o u p)$.

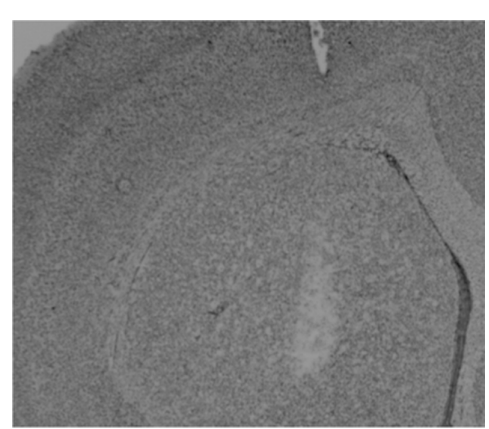

FIGURE 4 | Image captured with a CCD camera of a thionin-stained section illustrating a cannula track in the dorsocentral striatum illuminated on a light box. Note the lack of necrosis surrounding the injector track. stored, and released from corticostriatal neurons (Altar et al., 1997). As for other neuropeptides, BDNF is stored and released from dense core vesicles in an action potential-dependent manner (Kohara et al., 2001; Balkowiec and Katz, 2002) that requires more intense stimulation than that of glutamate from small clear vesicles (Lessman, 1998; Carvalho et al., 2008). Thus, it is reasonable that TrkB phosphorylation was not evident 15 min after AMPH but was detected $2 \mathrm{~h}$ later if BDNF release occurred in a delayed, stimulusdependent manner. This time course is consistent with the peak in motor activity and extracellular glutamate levels in the striatum that occurs between 30 and $90 \mathrm{~min}$, in contrast to extracellular dopamine levels that peak between 15 and $30 \mathrm{~min}$ after this dose of AMPH (Gray et al., 1999; Rawls and McGinty, 2000).

The elevation of $\mathrm{p}$-TrkB in the NAc and $\mathrm{CPu} 2 \mathrm{~h}$ after acute AMPH contrasts with a recent study indicating that pan-TyrTrkB was induced by a single cocaine injection in the NAc of mice 
(Crooks et al., 2010). However, in their report, the increase of p-TrkB immunoreactivity was observed 9-12 h, but not $10 \mathrm{~min}$ or $3 \mathrm{~h}$, after cocaine. The discrepant timepoint for TrkB activation in the two studies may be due to the different species and/or psychostimulants used. In addition to the pan-activation of TrkB on tyrosine sites in this study, the induction of $\mathrm{p}$-TrkB 816 was detected in the NAc and CPu after acute AMPH administration. p-TrkB 816 triggers PLC $\gamma$-mediated signaling (Chao, 2003; Reichardt, 2006). Thus, it is plausible that the TrkB-PLC $\gamma$ pathway in part mediates the BDNF-regulated intracellular transduction in response to acute AMPH. However, other TrkB-related signaling (e.g., Akt and ERK) should be further investigated.

K252a enhanced AMPH-induced vertical activity without altering horizontal ambulation (measured as total distance traveled). Vertical activity is part of a rat's exploratory repertoire that is thought to be mediated predominantly by the CPu and predominates after high doses or repeated administration of AMPH that produce stereotypical rearing behavior (Kelly et al., 1975; Lyon and Robbins, 1975). Thus, augmentation of vertical activity by K252a may represent a disinhibition of rearing in response to a moderate dose of AMPH that normally is tempered by activation of Trk receptor tyrosine kinase, or possibly another kinases inhibited by K252a. Since total distance traveled was not altered, overall exploratory locomotion was increased by the combination of K252a and AMPH. Of the many different receptor antagonists and agonists we have investigated in this paradigm over the years (Wang and McGinty, 1999; McGinty et al., 2010), K252a is the first one that has yielded this behavioral profile in combination with acute AMPH. As for intracellular kinases, PKA and MEK inhibitors upstream of ERK
MAPK both reduce AMPH-induced horizontal and vertical activity (Sutton et al., 2000; Shi and McGinty, 2006) whereas the PI-3 kinase inhibitor, wortmannin, decreases AMPH-induced vertical activity and increases horizontal activity (Shi et al., in preparation). However, although K252a has a higher affinity for tyrosine kinases, particularly Trk family receptors, than ser/thr kinases in vitro (Berg et al., 1992; Tapley et al., 1992; Martin et al., 2011), conclusions about the effects of K252a in this in vivo study should be drawn with caution and considered preliminary until confirmed by other Trk inhibitors or BDNF scavengers.

K252a suppressed AMPH-induced PPD, but not PPE, mRNA expression in the striatum. Since PPD is expressed only in the D1-regulated, direct pathway, and PPE mRNA only in the indirect pathway in the $\mathrm{CPu}$ (Gerfen, 1992), the data suggest that K252a acts predominantly via kinase cascades in direct pathway MSNs. It is less likely that inhibition of kinase cascades in indirect pathway MSNs leads to suppression of AMPH-induced PPD mRNA in direct pathway neurons. The selective effect of K252a on PPD vs. PPE gene expression also diminishes the likelihood that the K252a effects are mediated by ser/thr kinases stimulated by the major striatal regulators like D1, group I metabotropic glutamate, or muscarinic receptors because antagonists of these pathways block AMPH-induced PPD and PPE gene expression (Wang and McGinty, 1996a,b, 1999; McGinty et al., 2010). Alternatively, consideration must be given to the possibility that tyrosine kinase inhibition mediated by TrkB receptors underlies these K252a effects. However, since all MSNs in the striatum express TrkB receptors (Freeman et al., 2003; Lobo et al.,2010), it is unclear how selectivity of TrkB receptor stimulation would be accomplished unless it enhanced activity in one pathway

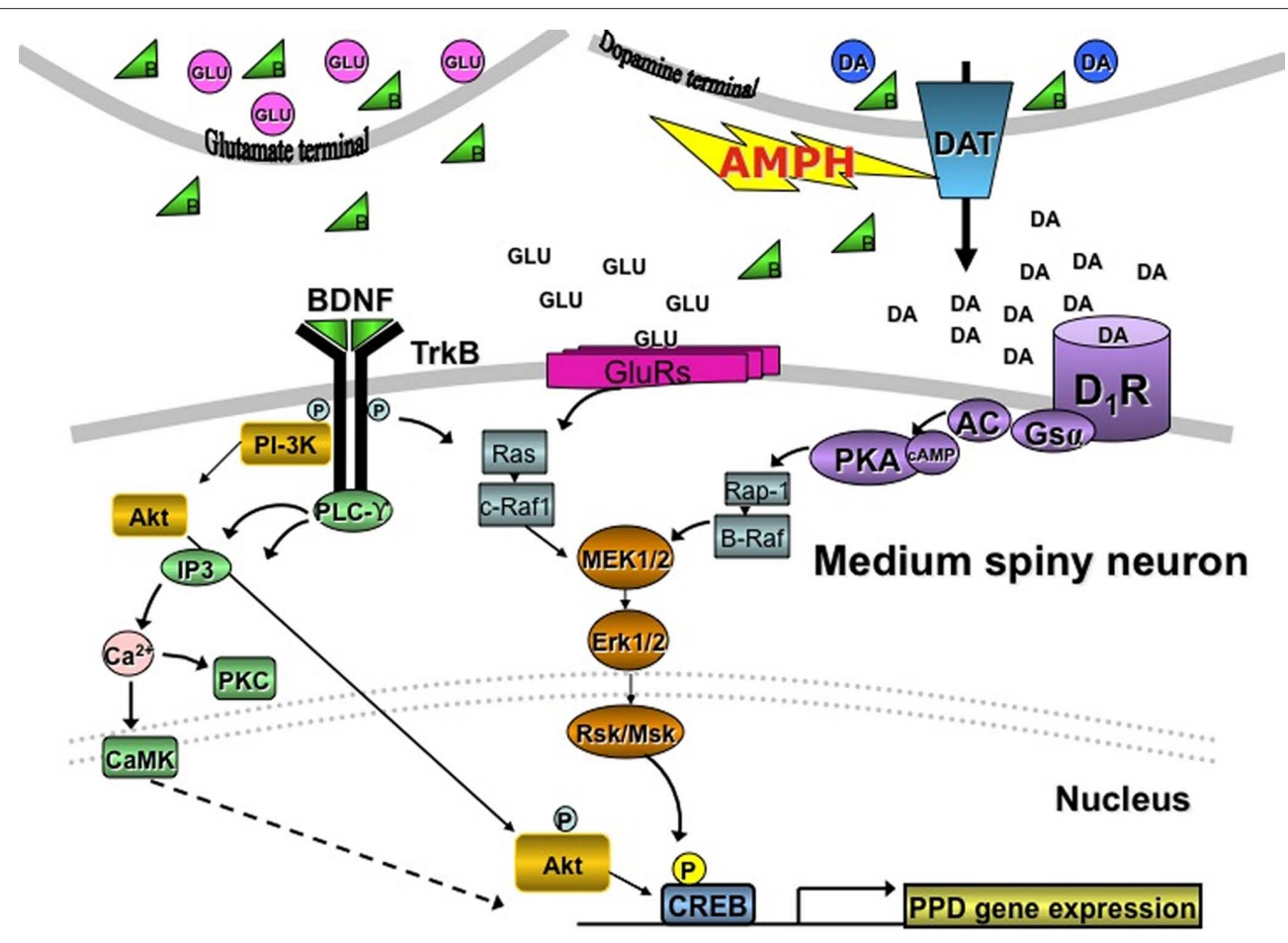

FIGURE 5 | Putative crosstalk between D1andTrkB receptors in striatal direct pathway neurons controlling PPD mRNA expression. 
and dampened activity in the other. Support for this idea stems from evidence that a TrkB receptor knockout exclusively in the direct pathway enhances, whereas a TrkB receptor knockout in indirect pathway neurons dampens, cocaine-induced behavioral sensitization and conditioned place preference in mice despite greater abundance of TrkB receptors on indirect pathway neurons (Lobo et al., 2010). Further, the expression of D1 and D3, but not D2, receptors is decreased in TrkB knockout mice (Guillin et al., 2001; Do et al., 2007; Saylor and McGinty, 2010), suggesting a dominant positive tone exerted by TrkB receptors on dorsal and ventral striatal neurons bearing these receptors. Thus, it is possible that by increasing BDNF release from dopamine and glutamate terminals in the striatum that TrkB receptors contribute to the behavioral and neurochemical sequelae in direct pathway neurons as depicted in Figure 5.

\section{REFERENCES}

Altar, C. A., Cai, N., Bliven, T., Juhasz, M., Conner, J. M., Acheson, A. L., Lindsay, R. M., and Wiegand, S. J. (1997). Anterograde transport of brainderived neurotrophic factor and its role in the brain. Nature 393, 856-860.

Arenas, E., Akerud, P., Wong, V., Boylan, C., Persson, H., Lindsay, R. M., and Altar, C. A. (1996). Effects of BDNF and NT- $4 / 5$ on striatonigral neuropeptides or nigral GABA neurons in vivo. Eur. J. Neurosci. 8, 1707-1717.

Balkowiec, A., and Katz, D. (2002). Cellular mechanisms regulating activity-dependent release of native brain-derived neurotrophic factor from hippocampal neurons. $J$. Neurosci. 22, 10399-10407.

Berg, M. M., Sternberg, D. W., Parada, L. F., and Chao, M. V. (1992). K-252a inhibits nerve growth factor-induced trkproto-oncogene tyrosine phosphorylation and kinase activity. J. Biol. Chem. 267, 13-16.

Carvalho, A. L., Caldeira, M. V., Santos, S. D., and Duarte, C. B. (2008). Role of brain-derived neurotrophic factor at glutamatergic synapses. $\mathrm{Br}$. J. Pharmacol. 153, S310-S324.

Chao, M. V. (2003). Neurotrophins and their receptors: a convergent point for many signalling pathways. Nat. Rev. Neurosci. 4, 299-309.

Cole, R. L., Konradi, C., Douglass, J., and Hyman, S.E. (1995). Neuronal adaptation to amphetamine and dopamine: molecular mechanisms of prodynorphin gene regulation in rat striatum. Neuron 14, 813-823.

Crooks, K. R., Kleven, D. T., Rodriguez, R. M., Wetsel, W. C., and McNamara, J. O. (2010). TrkB signaling is required for behavioral sensitization and conditioned place preference induced by a single injection of cocaine. Neuropharmacology 58, 1067-1077.

Do, T., Kerr, B., and Kuzhikandathil, E. V. (2007). Brain-derived neurotrophic factor regulates the expression of D1 dopamine receptors. J. Neurochem. 100, 416-428.

Freeman, A. Y., Soghomonian, J.-J., and Pierce, R. C. (2003). Tyrosine kinase $\mathrm{B}$ and $\mathrm{C}$ receptors in the neostriatum and nucleus accumbens are colocalized in enkephalin-positive and enkephalin-negative neuronal profiles and their expression is influenced by cocaine. Neuroscience 117, 147-156.

Gerfen, C. R. (1992). The neostriatal mosaic: multiple levels of compartmental organization. Trends Neurosci. $15,133-139$.

Gray, A. M., Rawls, S. M., Shippenberg, T. S., and McGinty, J.F. (1999). The kappa opioid agonist, U-69593, decreases acute amphetamine-evoked behaviors and calcium-dependent dialysate levels of dopamine and glutamate in the ventral striatum. J. Neurochem. 73 , 1066-1074.

Guillin, O., Diaz, J., Carroll, P., Griffon, N., Schwartz, J.C., and Sokoloff, P. (2001). $\mathrm{BDNF}$ controls dopamine $\mathrm{D} 3$ receptor expression and triggers behavioural sensitization. Nature 411, 86-89.

Huang, Y. Z., Pan, E., Xiong, Z. Q., and McNamara, J. O. (2008). Zincmediated trans-activation of TrkB potentiates the hippocampal mossy fiber-CA3 pyramid synapse. Neuron $57,546-558$.

Jeanneteau, F., Garabedian, M. J., and Chao, M. V. (2008). Activation of Trk neurotrophin receptors by glucocorticoids provides a neuroprotective effect. Proc. Natl. Acad. Sci. U.S.A. 105, 4862-4867.

Kelly, P. H., Seviour, P. W., and Iversen, S. D. (1975). Amphetamine and apomorphine responses in the rat following 6-OHDA lesions of the nucleus accumbens septi and corpus striatum. Brain Res. 94, 507-522.

Kohara, K., Kitamura, A., Morishima, M., and Tsumoto, T. (2001). Activitydependent transfer of brain-derived neurotrophic factor to postsynaptic neurons. Science 291, 2419-2423.

\section{CONCLUSION}

Taken together, these data suggest that AMPH indirectly stimulates BDNF/TrkB receptors and that K252a augments acute AMPH-induced vertical activity and inhibits PPD gene expression via an undefined kinase cascade, possibly TrkB-coupled, in the D1-regulated, direct pathway. The possibility that this AMPHstimulated kinase cascade involves BDNF/TrkB, dopamine, and glutamate interactions in the striatum requires further exploration.

\section{ACKNOWLEDGMENTS}

The authors thank Moses Chao, Ph.D. for p806-TrkB antiserum and Matthew C. Hearing, Ph.D., Sarah A. Eisenstein, Ph.D., and Stacey Sigmon for advice and technical assistance. Supported by RO1 DA03982.

Konradi, C., Leveque, J. C., and Hyman, S. E. (1996). Amphetamine and dopamine-induced immediate early gene expression in striatal neurons depends on postsynaptic NMDA receptors and calcium. J. Neurosci. 16, 4231-4239.

Le Foll, B., Diaz, J., and Sokoloff, P. (2005). A single cocaine exposure increases BDNF and D3 receptor expression: implications for drug-conditioning Neuroreport 16, 175-178.

Lessman, V. (1998). Neurotrophindependent modulation of glutamatergic synaptic transmission in the mammalian CNS. Gen. Pharmacol.31, 667-674.

Lobo, M. K., Covington, H. E. III, Chaudhury, D., Friedman, A. K., Sun, H., Dietz, D. M., Zaman, S., Koo, J. W., Kennedy, P. J., Mouzon, E., Mogri, M., Neve, R. L., Deisseroth, K., Han, M.-H., and Nestler, E. J. (2010). Cell type specific loss of BDNF signaling mimics optogenetic control of cocaine reward. Science 330, 385-390.

Lyon, M., and Robbins, T. (1975). The action of central nervous system stimulant drugs: a general theory concerning amphetamine effects. Curr. Dev. Psychopharmacol. 2, 70-63.

Martin, K. J., Shapiro, N., Traynor, R. Elliott, M., and Arthur, S. C. (2011) Comparison of the specificity of Trk inhibitors in recombinant and neuronal assays. Neuropharmacology61,148-155.

McGinty, J. F., Shi, X. D., Schwendt, M., Saylor, A., and Toda, S. (2008). Regulation of psychostimulantinduced signaling and gene expression in the striatum. J. Neurochem. 104, 1440-1449.

McGinty, J. F., Whitfield, T. W., and Berglind, W. J. (2010). Brain-derived neurotrophic factor and cocaine addiction. Brain Res. 1314, 183-193.

Meredith, G. E., Callon, S., and Scheuer, D. A. (2002). Brain-derived neurotrophic factor expression is increased in the rat amygdala, piriform cortex and hypothalamus following repeated amphetamine administration. Brain Res. 949, 218-227.

Numan, S., and Seroogy, K. B. (1999). Expression of trkB and trkC mRNAs by adult midbrain dopamine neurons: a double label in situ hybridization study. J. Comp. Neurol. 403, 295-308.

Ou, L. C., and Gean, P. W. (2006). Regulation of amygdala-dependent learning by brain-derived neurotrophic factor is mediated by extracellular signal regulated kinase and phosphatidylinositol-3-kinase. Neuropsychopharmacology 31, 287-296.

Patapoutian, A., and Reichardt, L. F. (2001). Trk receptors: mediators of neurotrophin action. Curr. Opin. Neurobiol. 11, 272-280.

Poo, M. (2001). Neurotrophins as synaptic modulators. Nat. Rev. Neurosci. 2, 24-32.

Rattiner, L. M., Davis, M., French, C. T., and Ressler, K. J. (2004). Brain-derived neurotrophic factor and tyrosine kinase receptor B involvement in amygdala-dependent fear conditioning. J. Neurosci. 24, 4796-4806.

Rawls, S. M., and McGinty, J. F. (2000). Delta opioid receptors regulate calcium-dependent, amphetamineevoked glutamate levels in the striatum: an in vivo microdialysis study. Brain Res. 861, 296-304.

Reichardt, L. F. (2006). Neurotrophinregulated signaling pathways. Philos. Trans. R. Soc. Lond. B Biol. Sci. 361, 1545-1564.

Rocamora, N., Welker, E., Pascual, M., and Soriano, E. (1996). Upregulation of BDNF mRNA expression in the barrel cortex of adult mice after sensory stimulation. J. Neurosci. 16, 4411-4419.

Russo, S. J., Mazei-Robison, M. S., Ables, J. L., and Nestler, E. J. (2008). Neurotrophic factors and structural plasticity in addiction. Neuropharmacology 56, 73-82. 
Sauer, H., Campbell, K., Wiegand, S. J., Lindsay, R. M., and Bjorklund, A. (1994). Brain-derived neurotrophic factor enhances striatal neuropeptide expression in both the intact and the dopamine-depleted rat striatum. Neuroreport 5, 609-612.

Saylor, A. J., and McGinty, J. F. (2008). Amphetamine-induced locomotion and gene expression are altered in BDNF heterozygous mice. Genes Brain Behav. 7, 906-914.

Saylor, A. J., and McGinty, J. F. (2010). An intra-striatal brain-derived neurotrophic factor infusion restores striatal gene expression in Bdnf heterozygous mice. Brain Struct. Funct. 215, 97-104.

Saylor, A. J., Meredith, G. E., Vercillo, M. S., Zahm, D. S., and McGinty, J. F. (2006). BDNF heterozygous mice demonstrate age-related changes in striatal and nigral gene expression. Exp. Neurol. 199, 362-372.

Seroogy, K. B., Lundgren, K. H., Tran, T. M., Guthrie, K. M., Isackson, P. J., and Gall, C.M.(1994). Dopaminergic neurons in rat ventral midbrain express brain-derived neurotrophic factor and neurotrophin-3 mRNAs. J. Comp. Neurol. 342, 321-334.

Shi, X., and McGinty, J. F. (2006). ERK MAP kinase inhibitors decrease amphetamine-induced behavior and neuropeptide gene expression in the striatum. Neuroscience 138, 1289-1298.

Simpson, J. N., Wang, J. Q., and McGinty, J. F. (1995). Repeated amphetamine administration induces a prolonged augmentation of phosphorylatedCREB and Fos-related antigen immunoreactivity in rat striatum. Neuroscience 69, 441-457.

Smith, A. J. W., and McGinty, J. F. (1994). Acute amphetamine and methamphetamine alter opioid peptide mRNA expression in the rat striatum. Brain Res. Mol. Brain Res. 21, 359-362.

Sun, W. L. Zhou, L., Quinones-Jenab, V., and Jenab, S. (2009). Cocaine effects on dopamine and NMDA receptors interactions in the striatum of Fischer rats. Brain Res. Bull. 80, 377-381.

Sutton, M.A., McGibney, K., and Beninger, R. J. (2000). Conditioned locomotion in rats following amphetamine infusion into the nucleus accumbens: blockade by coincident inhibition of protein kinase. Behav. Pharmacol. 11, 365-376.

Tapley, P., Lamballe, F., and Barbacid, M. (1992). K252a is a selective inhibitor of the tyrosine protein kinase activity of the trk receptor family of oncogenes and neurotrophin receptors. Oncogene 7, 371-381.

Valjent, E., Pascoli, V., Svenningsson, P., Paul, S., Enslen, H., Corvol, J. C., Stipanovich, A., Caboche, J., Lombroso, P. J., Nairn, A. C., Greengard, P., Herve, D., and Girault, J. A. (2005). Regulation of a protein phosphatase cascade allows convergent dopamine and glutamate signals to activate ERK in the striatum. Proc. Natl. Acad. Sci. U.S.A. 102, 491-496.
Vanhoutte, P., Barnier, J. V., Guibert, B. Pages, C., Besson, M. J., Hipskind, P. A., and Caboche, J. (1999). Glutamate induces phosphorylation of Elk-1 and CREB, along with c-fos activation, via an extracellular signal-regulated kinase-dependent pathway in brain slices. Mol. Cell. Biol. 19, 136-146.

Wang, J. Q., and McGinty, J. F. (1995). Dose-dependent alterations in zif/268 and preprodynorphin mRNA expression induced by amphetamine or methamphetamine in rat brain. $J$. Pharmacol. Exp. Ther. 273, 909-917.

Wang, J. Q., and McGinty, J. F. (1996a). D1 and D2 receptor regulation of preproenkephalin and preprodynorphin mRNA in rat striatum following acute injection of amphetamine or methamphetamine. Synapse 22 114-122.

Wang, J. Q., and McGinty, J. F. (1996b) Intrastriatal injection of the metabotropic glutamate receptor antagonist MCPG attenuates acute amphetamine-stimulated neuropeptide mRNA expression in rat striatum. Neurosci. Lett. 218, 13-16.

Wang, J. Q., and McGinty, J. F. (1999). Glutamate-dopamine interactions mediate the effects of psychostimulant drugs. Addict. Biol. 4, 143-152.

Wang, J. Q., Smith, A. W. S., and McGinty, J. F. (1995). A single injection of amphetamine or methamphetamine induces dynamic alterations in c-fos, zif/268 and preprodynorphin
mRNA expression in rat forebrain. Neuroscience 68, 83-95.

Whitfield, T. W., Shi, X., Sun, W.-L., and McGinty, J. F. (2011). The suppressive effect of an intra-prefrontal cortical infusion of BDNF on cocaine-seeking is Trk receptor and extracellular signal-regulated protein kinase mitogen-activated protein kinase dependent. J. Neurosci. 32, 834-842.

Conflict of Interest Statement: The authors declare that the research was conducted in the absence of any commercial or financial relationships that could be construed as a potential conflict of interest.

Received: 28 February 2011; paper pending published: 27 April 2011; accepted: 27 June 2011; published online: 21 July 2011.

Citation: McGinty JF, Bache AJ, Coleman NT and Sun W-L (2011) The role of BDNF/ TrkB signaling in acute amphetamineinduced locomotor activity and opioid peptide gene expression in the rat dorsal striatum. Front. Syst. Neurosci. 5:60. doi: 10.3389/fnsys.2011.00060

Copyright (C) 2011 McGinty, Bache, Coleman and Sun. This is an open-access article subject to a non-exclusive license between the authors and Frontiers Media $S A$, which permits use, distribution and reproduction in other forums, provided the original authors and source are credited and other Frontiers conditions are complied with. 